\title{
Significant increase in acute subdural hematoma in octo- and nonagenarians: surgical treatment, functional outcome, and predictors in this patient cohort
}

\author{
*Sae-Yeon Won, MD, ${ }^{1}$ Daniel Dubinski, MD, MSc, ${ }^{1}$ Nina Brawanski, MD, ${ }^{1}$ \\ Adam Strzelczyk, MD, MHBA, ${ }^{2,3}$ Volker Seifert, MD, PhD, ${ }^{1}$ Thomas M. Freiman, MD, ${ }^{1}$ and \\ Juergen Konczalla, MD1 \\ Departments of ${ }^{1}$ Neurosurgery and ${ }^{2}$ Neurology, and ${ }^{3}$ Epilepsy Center Frankfurt Rhine-Main, University Hospital, \\ Goethe-University, Frankfurt am Main, Germany
}

OBJECTIVE Acute subdural hematoma (aSDH) is a common disease increasing in prevalence given the demographic growth of the aging population. Yet, the benefit of surgical treatment for aSDH and the subsequent functional outcome in elderly patients (age $\geq 80$ years) remain unclear. Therefore, the aims of this study were to evaluate the incidence of aSDH in patients 80 years or older, determine overall functional outcome, identify predictors of an unfavorable or favorable outcome, and establish specific risk factors for seizures.

METHODS The authors retrospectively analyzed patients 80 years and older who presented with isolated aSDH in the past 10 years at their institution. The following parameters were assessed: baseline characteristics, clinical status on admission and 24 hours after surgery, and clinical course. Functional outcome was assessed at discharge and the 3-month follow-up (FU).

RESULTS In the period from January 2007 to December 2016, 165 patients with aSDH were admitted to the authors' institution. Sixty-eight patients (41.2\%) were 80 years old or older, and the mean age overall was 85 years (range $80-96$ years). The incidence of aSDH in the elderly had significantly increased over past decade, with more than $50 \%$ of patients admitted to our institution for aSDH now being 80 years or older. The overall mortality rate was $28 \%$ at discharge and $48 \%$ at the FU. Independent predictors of an unfavorable outcome at discharge were a GCS score $\leq 8$ at 24 hours after operation $(p<0.001)$ and pneumonia $(p<0.02)$. At the FU, a GCS score $\leq 8$ at 24 hours after operation $(p<0.001)$ and cumulative comorbidities $(\geq 5 ; p<0.05$ ) were significant independent predictors. All patients with more than 6 comorbidities had died by the FU. Surgical treatment in comatose compared to noncomatose patients had statistically significant, higher mortality rates at discharge and the FU. Still, $23 \%$ of the comatose patients and more than $50 \%$ of the noncomatose patients had a favorable outcome at the FU $(p=0.06)$.

CONCLUSIONS The number of octo- and nonagenarians with aSDH significantly increased over the last decade. These patients can achieve a favorable outcome, especially those with a noncomatose status and fewer than 5 comorbidities. Surgical and nonsurgical treatment of octo- and nonagenarians during and after discharge should be optimized to increase clinical improvement.

https://thejns.org/doi/abs/10.3171/2017.7.FOCUS17417

KEY WORDS acute subdural hematoma; elderly patient; octogenarian; nonagenarian; surgical treatment; functional outcome; predictor

$\Lambda$ CUTE subdural hematoma (aSDH) is a common disease increasing in prevalence and cost in the last few decades. ${ }^{5}$ In particular, because of extended life expectancy and increasing need for anticoagulation therapy, aSDH in elderly patients is becoming more criti- cal. The prognosis of aSDH depends on multiple factors such as patient age, clinical status, signs of cerebral herniation, hematoma size, type of treatment, seizures, and time until treatment; prognosis and functional outcome in elderly patients in particular remain unclear. , $, 8,19,21,25,29^{2}$

ABBREVIATIONS aSDH = acute subdural hematoma; EEG = electroencephalography; FU = 3-month follow-up; GCS = Glasgow Coma Scale; GOS = Glasgow Outcome Scale; TBI = traumatic brain injury.

ACCOMPANYING EDITORIAL DOI: 10.3171/2017.8.FOCUS17529.

SUBMITTED June 19, 2017. ACCEPTED July 27, 2017

INCLUDE WHEN CITING DOI: 10.3171/2017.7.FOCUS17417.

* Drs. Freiman and Konczalla contributed equally to this work and share senior authorship. 
Reported mortality rates for aSDH have ranged between $22 \%$ and $60 \%$, and even higher morbidity and mortality rates have been reported in elderly patients. ${ }^{2,7,15,16,18,23}$ In reports from the 1980s and 1990s, mortality rates for aSDH patients older than 65 years of age range from $74 \%$ to $88 \%$, indicating devastating outcomes. ${ }^{2,8,14}$ Over time, improved medical developments and increasing health care resources could have changed the outcomes. ${ }^{16,26,28}$ However, elderly patients over 80 years of age with isolated aSDH are rarely mentioned in studies. Indeed, octoand nonagenarians were the scientific "forgotten ones" in the past.

Therefore, we conducted this study to evaluate functional outcomes in surgically and nonsurgically treated patients with isolated aSDH who were 80 years of age or older. Furthermore, predictors of an unfavorable outcome were identified to assess the influence of baseline clinical characteristics and in-hospital treatment on functional outcome.

\section{Methods \\ Study Population and Data Collection}

A retrospective study was conducted using our electronic patient database, and all patients with an age $\geq 80$ years and isolated aSDH in the period between January 2007 and December 2016 were identified. Further study inclusion criteria were isolated aSDH as the primary admission diagnosis and a hospital stay $\geq 24$ hours. Patients with other types of SDH and hospital discharge in less than 24 hours were excluded.

While examining the medical records, we collected information on the following parameters: patient age, sex, timing of operation, duration of hospital stay, admission status, Glasgow Coma Scale (GCS) score 24 hours after operation or 24 hours after admission for the conservatively treated patients, hematoma side, surgical procedures, rebleeding rate leading to reoperation, anticoagulation therapy, seizures, and comorbidities. Preoperative comorbidities were defined as follows: hypertension, atrial fibrillation, Type 2 diabetes, cardiovascular disease, respiratory insufficiency, renal failure, hematological disease, metabolic disease, previous stroke, pneumonia, and sepsis. Admission CT scans were used to evaluate hematoma length, width, and depth at the widest diameter and midline shift in the height of the pineal gland. For hematoma volume calculation, the previously reported volume-estimating formula of $\mathrm{ABC} / 2$ was applied. ${ }^{6}$ Electroencephalography (EEG) recordings were reviewed by experienced, board-certified (EEG) neurologists who were blinded to functional outcomes. Seizure was defined as clinical manifestation, ictal patterns in the EEG recordings, or clinical suspicion with interictal discharges in the EEG recordings.

The primary functional outcome was measured with the Glasgow Outcome Scale (GOS) at hospital discharge, dichotomized as favorable (GOS Scores 4-5) and unfavorable (GOS Scores 1-3) outcomes. The secondary outcome was the GOS score at the 3-month follow-up (FU). A structured telephone survey was administered by two independent physicians after obtaining informed consent from the patient for participation in this study.

\section{Study Design}

This study was a retrospective analysis at a single center. The aims of the study were to evaluate the incidence of aSDH in patients 80 years of age or older in the last decade, to determine the overall functional outcome, to identify predictors of an unfavorable or a favorable functional outcome, and to identify specific risk factors for seizures in elderly patients since the occurrence of seizures is one of the frequent complications and has been shown to be an independent predictor of a poor functional outcome. ${ }^{5}$

\section{Statistical Analysis}

GraphPad Prism (version 6.0, GraphPad Software Inc.) and IBM SPSS Statistics (version 22, IBM Corp.) were used for data analysis. For trend statistics, the MantelHaenszel test was used. In addition, univariate and multivariate analyses were performed. Multivariable logistic regression analysis was conducted to obtain independent risk factors for an unfavorable outcome. For parametric parameters, an unpaired t-test was used. For nonparametric parameters, variables were analyzed in a contingency table using Fisher's exact test. To assess the impact of the variables, odds ratios with $95 \%$ confidence intervals were calculated. All tests were 2 -sided, and a p value $\leq 0.05$ was considered statistically significant.

\section{Results}

Over the study period, 68 (41.2\%) of 165 patients with isolated aSDH were 80 years of age or above. Among them were 8 patients who were 90 years or older. In the last decade, there has been a significant shift $(\mathrm{p}=0.02)$ to an older age ( $\geq 80$ years) in patients with aSDH, from $31.6 \%$ (2007-2008) to over 55\% (2015-2016; Fig. 1).

Mean age among the 68 patients was 85 years, and 39 patients $(57 \%)$ were female. Sixteen patients $(24 \%)$ had a favorable outcome at hospital discharge, and 7 of them (10\%) had an excellent recovery (Fig. 2). All 68 patients had at least 1 significant comorbidity, and 6 patients (9\%) had more than 6 comorbidities. In a subgroup analysis, patients with fewer than 5 comorbidities had a favorable out-

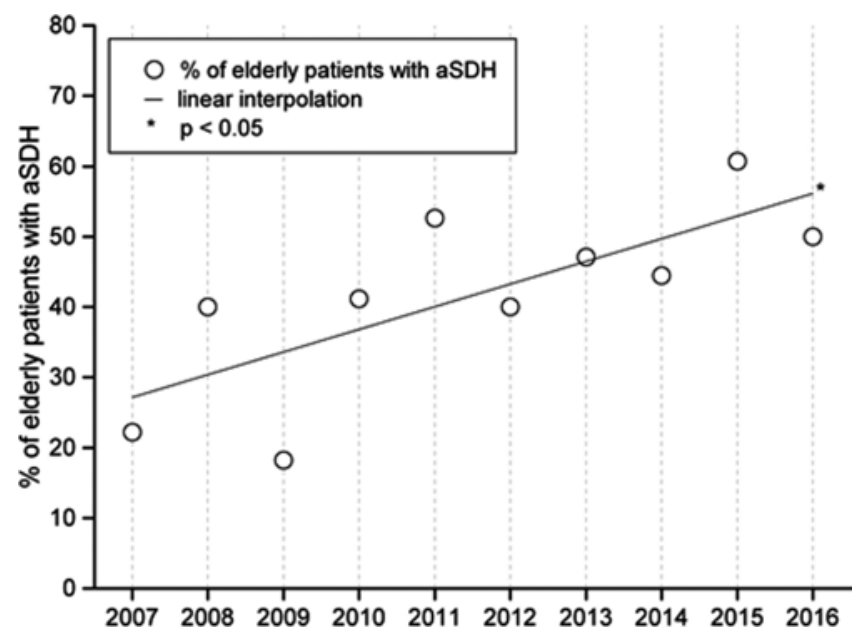

FIG. 1. Incidence of aSDH in elderly patients ( $\geq 80$ years of age) in the last decade. 


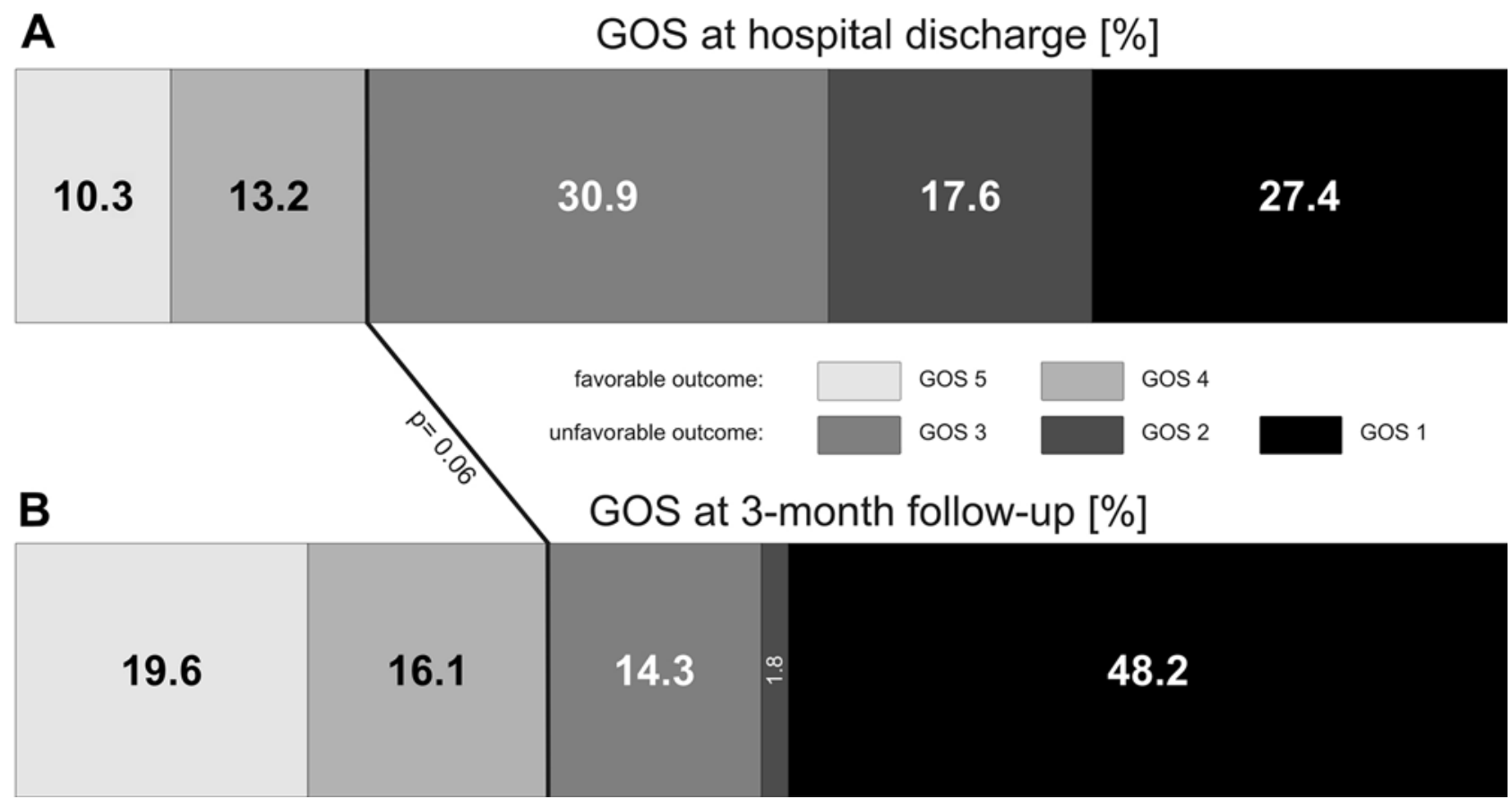

FIG. 2. A: Functional outcome according to the GOS at hospital discharge. A GOS score of $4-5$ was defined as a favorable outcome and a GOS score of 1-3 as an unfavorable outcome. B: Functional outcome according to the GOS at the FU.

come $(32.3 \%)$ more often than the patients with 5 or more comorbidities (16.2\%) at hospital discharge (Fig. 3A).

Predictors of an unfavorable outcome at discharge were the following: admission GCS score $\leq 8$, GCS score $\leq 8$ at 24 hours after operation, rebleeding, and pneumonia. In the multivariate analysis, GCS score $\leq 8$ at 24 hours after operation ( $\mathrm{p}<0.001$, OR 15.4) and pneumonia ( $\mathrm{p}$ $<0.02$, OR 6.2) were significant independent predictors (Nagelkerke $\mathrm{R}^{2}=0.411$; Table 1).

At 3 months after treatment, $12(17.6 \%)$ of 68 patients were not included in further analysis. After the acute management phase, these 12 patients from other countries were transported back to their own countries. Among these patients, however, $4(33.3 \%)$ had a favorable outcome at discharge, which is a better outcome than the average $(24 \%)$.

Therefore, 56 patients were eligible for FU analysis. There was a positive trend toward a favorable outcome $(36 \%, p=0.06)$; however, the mortality rate significantly increased from $28 \%$ at hospital discharge to $48 \%$ at the FU ( $p=0.03$, OR 2.4; Fig. 2). There was a significant improvement in outcome in the group with fewer than 5 comorbidities as compared with the group with 5 or more comorbidities $(56 \%$ vs $19.4 \%, \mathrm{p}<0.0001)$. All patients with more than 6 comorbidities ( 6 patients) had died by the FU, indicating a $100 \%$ mortality rate (Fig. 3B). All 8 nonagenarians (age $\geq 90$ years) had fewer than 6 comorbidities, and more than $50 \%$ had a favorable outcome at FU. Predictors of an unfavorable outcome at the FU were as follows: admission GCS score $\leq 8$, GCS score $\leq 8$ at 24 hours after operation, seizures, and 5 or more and 6 or more comorbidities. Atrial fibrillation and Type 2 diabetes as comorbidities and a shorter hospital stay tended toward an unfavorable outcome without reaching significance. Among the predictors of an unfavorable outcome at FU, a
GCS score $\leq 8$ at 24 hours after operation $(\mathrm{p}<0.0001$, OR 18.2) and comorbidities $\geq 5$ ( $\mathrm{p}<0.05$, OR 9.7) were shown to be independent predictors of an unfavorable outcome (Nagelkerke $\mathrm{R}^{2}=0.493$; Table 2).

Among surgically treated patients (via craniotomy or craniectomy), excluding the patients treated via delayed bur hole treatment (5 patients) or conservatively (7 patients), 24 patients $(42.8 \%$ ) were comatose (GCS score $\leq 6$ ) at admission. There was no significant difference between comatose and noncomatose patients in terms of a favorable outcome at hospital discharge; however, the mortality rate was significantly higher among comatose patients than the noncomatose patients at discharge as well as after 3 months $(37.5 \%$ vs $12.5 \%, \mathrm{p}=0.05$, OR 4.2 ; and $63.6 \%$ vs $30.4 \%, \mathrm{p}=0.04, \mathrm{OR} 4.0)$. At the FU, initially noncomatose patients had a positive trend toward a favorable outcome compared with the comatose patients $(52.2 \%$ vs $22.7 \%, \mathrm{p}=$ 0.06, OR 3.7), indicating better recovery. Five (7.4\%) of 68 patients were treated via delayed bur hole treatment since they were all on anticoagulation therapy and in moderate condition on admission without any neurological deficit. More than half of these 5 patients had a favorable outcome at discharge as well as at the FU, and 1 patient $(20 \%)$ died during the hospital stay as a result of septic shock triggered by fulminant pneumonia. Seven (10.3\%) of 68 patients were treated conservatively because of inoperable comorbidities (for example, pancytopenia, relevant aortic stenosis, concomitant infectious disease, and so forth). All conservatively treated patients in a comatose condition (4 patients) died during the hospital stay. Two conservatively treated patients in a noncomatose condition were alive at the FU, but only 1 patient had a moderate quality of life (GOS Score 3).

For seizure analysis, 4 (5.8\%) of 68 patients were ex- 
A

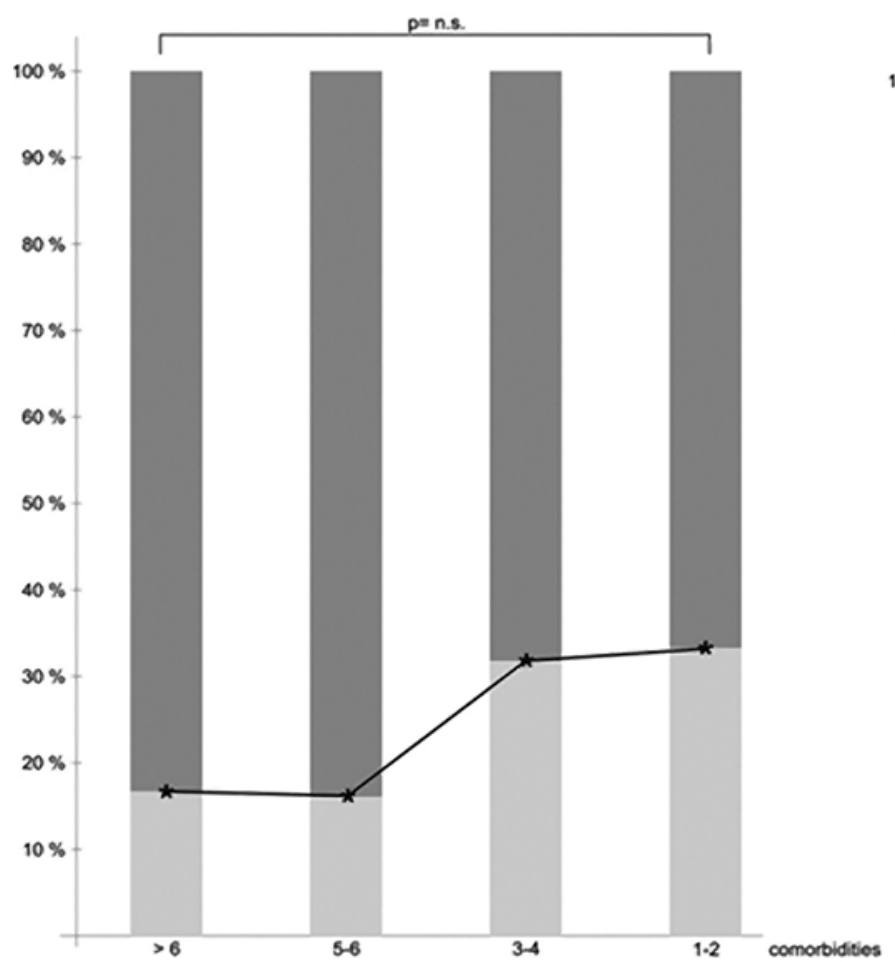

B

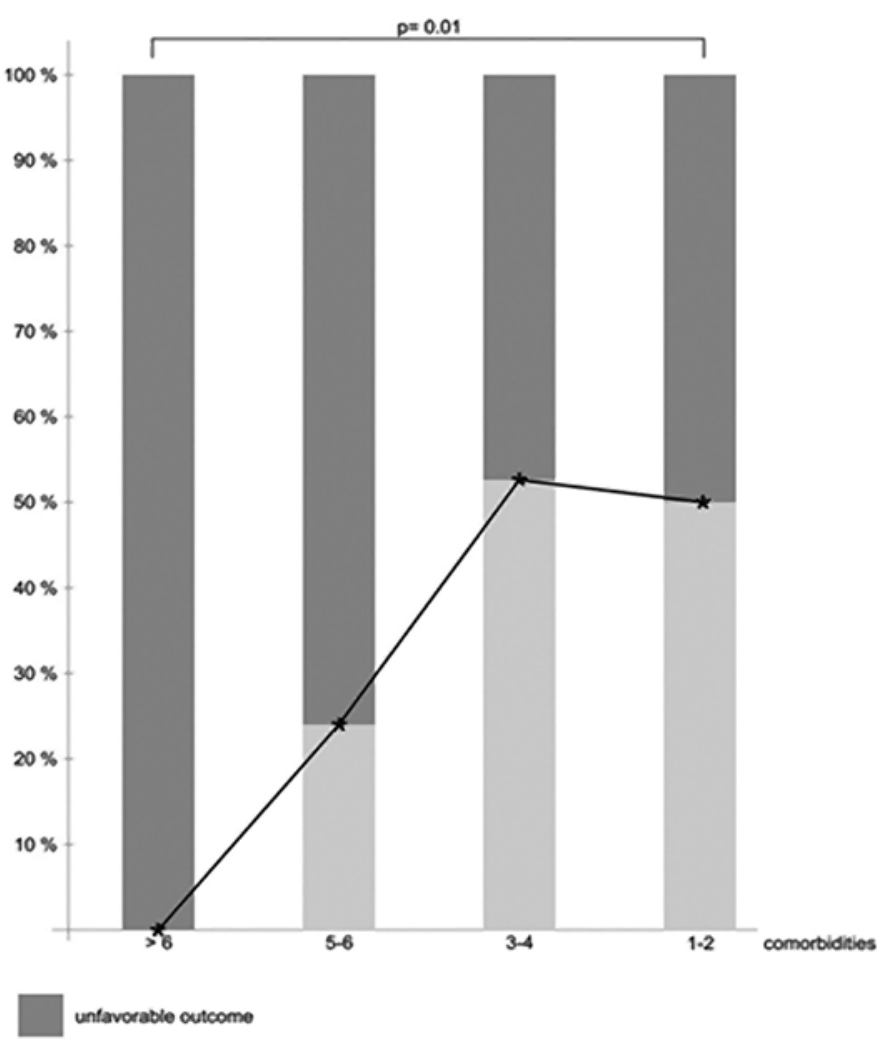

FIG. 3. A: Functional outcome at hospital discharge according to the number of comorbidities. B: Functional outcome at 3 months after discharge according to the number of comorbidities. n.s. = not significant.

cluded because of an uncertain seizure status. The overall incidence of clinical seizures and electrographic seizures on EEG was $43.7 \%$ (28 patients). None of the patients treated via delayed bur hole treatment had pre- or postoperative seizures. Predictors of seizures were as follows: GCS score $\leq 8$ at 24 hours after operation ( $\mathrm{p} \leq 0.02$, OR 3.5 ) and left-sided hematoma ( $\mathrm{p} \leq 0.02$, OR 3.6; Table 3).

\section{Discussion}

To date, the importance of aSDH in elderly patients is increasing given alterations in aging demographics. As we have shown in our study, the incidence of aSDH in elderly patients is continuously and significantly increasing, with more than $50 \%$ of our admitted patients with aSDH being 80 years or older. Therefore, we conducted what is one of the largest studies of elderly patients with aSDH to evaluate the outcome of aSDH in octo- and nonagenarians. Furthermore, by focusing on comorbidities and seizures, the latter being one of the frequent complications following surgical treatment, we analyzed predictors of a favorable or an unfavorable outcome.

Overall, 24\% of patients had a favorable outcome at discharge, and this rate increased to $36 \%$ at the FU; however, the mortality rate increased as well ( $28 \%$ vs $48 \%)$. In contrast to reports from the 1980s and 1990s with their nearly 90\% mortality rates, our rates indicate that functional outcome has improved dramatically over time., ${ }^{2,26}$ While the surgical treatment (decompressive craniectomy) of patients over 60 years of age with malignant middle cerebral artery stroke remains controversial because of the substantial postoperative disability (modified Rankin Scale Score $0-2$, DESTINY II clinical trial), elderly patients (age $\geq$ 80 years) with aSDH should be treated given our promising $36 \%$ favorable outcome rate at the FU. ${ }^{10}$ This better rate may reflect improvements in medical diagnostics and treatment over the years along with the development of standardized procedures. ${ }^{2,26}$ Similar results were shown by Taussky et al., who observed a favorable outcome in $41 \%$ of patients with aSDH and an age over 65 years. ${ }^{26}$ Interestingly, our results were also comparable to those in previous studies of younger patients with aSDH. ${ }^{13,14,18,21}$ There could be several reasons for this, but first, it is important to consider the definitions of an "elderly" and a "young" patient since these definitions are shifting as life expectancy increases. ${ }^{26}$ And besides age, it seems important to look at the comorbidities in elderly patients. In our study, all patients had at least 1 comorbidity, and because of the high number of comorbidities in octo- and nonagenarians, they were treated by an interdisciplinary team. This may have been a major factor in improving clinical outcome. At hospital discharge, there was a trend toward a favorable outcome in patients with fewer comorbidities $(<5)$, but statistical significance was not reached. In contrast, there was a significant difference in functional outcome after 3 months depending on the number of comorbidities. Indeed, all pa- 
TABLE 1. Favorable (GOS Scores 4-5) and unfavorable (GOS Scores 1-3) outcome at hospital discharge

\begin{tabular}{|c|c|c|c|c|c|c|c|}
\hline \multirow[b]{2}{*}{ Parameter } & \multirow{2}{*}{$\begin{array}{c}\text { All } \\
\text { (no. }[\%])\end{array}$} & \multirow{2}{*}{$\begin{array}{l}\text { Favorable Outcome } \\
\text { (no. [\%]) }\end{array}$} & \multirow{2}{*}{$\begin{array}{l}\text { Unfavorable Outcome } \\
\text { (no. [\%]) }\end{array}$} & \multicolumn{2}{|c|}{ Univariate Analysis } & \multicolumn{2}{|c|}{ Multivariate Analysis } \\
\hline & & & & OR $(95 \% \mathrm{Cl})$ & p Value & OR $(95 \% \mathrm{Cl})$ & $p$ Value \\
\hline No. of patients & 68 & 16 & 52 & & & & \\
\hline Mean age in yrs & $85.2 \pm 3.8$ & $85.4 \pm 3.7$ & $85.2 \pm 3.9$ & & NS & & \\
\hline Female sex & $39(57.4)$ & $7(43.8)$ & $32(61.5)$ & & NS & & \\
\hline Trauma & $49(72.0)$ & $12(75)$ & $37(71.2)$ & & NS & & \\
\hline $\begin{array}{l}\text { Timing of op after the 1st } 24 \\
\text { hrs of admission }\end{array}$ & $46(67.6)$ & $10(62.5)$ & $36(69.2)$ & & NS & & \\
\hline Mean hospital stay in days & $9.1 \pm 6.2$ & $9.6 \pm 5.3$ & $9.0 \pm 6.4$ & & NS & & \\
\hline \multicolumn{8}{|l|}{ Hematoma side } \\
\hline Lt & $30(44.1)$ & $9(56.2)$ & $21(40.4)$ & & NS & & \\
\hline Rt & $33(48.5)$ & $5(31.2)$ & $28(53.8)$ & & NS & & \\
\hline Both & $5(7.4)$ & $2(12.5)$ & $3(5.8)$ & & NS & & \\
\hline Mean hematoma vol in $\mathrm{cm}^{3}$ & $109.4 \pm 53.6$ & $112 \pm 58.3$ & $108.6 \pm 52.6$ & & NS & & \\
\hline Mean midline shift in mm & $8.3 \pm 6.4$ & $8.3 \pm 5.3$ & $8.3 \pm 6.8$ & & NS & & \\
\hline Admission GCS score $\leq 8$ & $34(50)$ & $4(25)$ & $30(57.7)$ & $4.1(1.2-14.4)$ & 0.04 & & NS \\
\hline GCS score $\leq 8$ at 24 hrs postop & $35(51.5)$ & $2(12.5)$ & $33(63.5)$ & $12.2(2.5-59.4)$ & $<0.0001$ & $15.4(2.9-80.8)$ & $<0.001$ \\
\hline Rebleeding & $12(17.6)$ & $0(0)$ & $12(23.1)$ & $10.2(1.2-88.7)$ & 0.05 & & NS \\
\hline Anticoagulation & $51(75)$ & $10(62.5)$ & $41(78.8)$ & & NS & & \\
\hline Seizure & $28(41.2)$ & $5(31.2)$ & $23(47.9)^{*}$ & & NS & & \\
\hline Preop comorbidities $\geq 5$ & $39(57.4)$ & $6(37.5)$ & $33(63.5)$ & $2.9(0.9-9.0)$ & 0.09 & & NS \\
\hline Preop comorbidities $\geq 6$ & $19(27.9)$ & $4(25)$ & $15(28.8)$ & & NS & & \\
\hline \multicolumn{8}{|l|}{ Preop comorbidities } \\
\hline Hypertension & $59(86.8)$ & $15(93.8)$ & $41(78.8)$ & & NS & & \\
\hline Atrial fibrillation & $30(44.1)$ & $6(37.5)$ & $41(78.8)$ & & NS & & \\
\hline Type 2 diabetes & $26(38.2)$ & $4(25)$ & $22(42.3)$ & & NS & & \\
\hline Cardiovascular disease & $44(64.7)$ & $11(68.8)$ & $33(63.5)$ & & NS & & \\
\hline Respiratory insufficiency & $20(29.4)$ & $5(31.2)$ & $15(28.8)$ & & NS & & \\
\hline Renal failure & $14(20.6)$ & $3(18.8)$ & $11(21.2)$ & & NS & & \\
\hline Hematological disease & $8(11.8)$ & $1(6.2)$ & $7(13.5)$ & & NS & & \\
\hline Metabolic disease & $51(75)$ & $11(68.8)$ & $40(76.9)$ & & NS & & \\
\hline Previous stroke & $8(11.8)$ & $2(12.5)$ & $6(11.5)$ & & NS & & \\
\hline Pneumonia & $34(50)$ & $3(18.8)$ & $31(59.6)$ & $6.4(1.6-25.2)$ & 0.04 & $6.2(1.4-28.2)$ & $<0.02$ \\
\hline Sepsis & $3(4.4)$ & $1(6.2)$ & $2(3.8)$ & & NS & & \\
\hline
\end{tabular}

NS = not significant.

Mean values are expressed with standard deviations. Significant independent predictors for an unfavorable outcome were a low GCS score 24 hours after operation ( $p$ $<0.001)$ and pneumonia $(p<0.02)$.

* Percentage based on a total of 48 patients since 4 patients were excluded due to an uncertain seizure status (no EEG).

tients with more than 6 comorbidities had died by the FU. Accordingly, having 5 or more comorbidities was an independent risk factor for an unfavorable outcome at FU (Table 2). A large epidemiological study reported major organ dysfunction as an independent predictor of mortality. ${ }^{1,24}$ Our results showed that the short-term prognosis (acute phase) in elderly patients depends not on comorbidities but on the severity of aSDH, which is expressed by pupillary abnormalities or unconsciousness. ${ }^{7}$ Nonetheless, long-term prognosis (3 months' follow-up) in survivors of aSDH also depends on the cumulating comorbidities.

Predictors of an unfavorable functional outcome at discharge were rebleeding, pneumonia, and a low GCS score $(\leq 8)$ at admission and 24 hours after operation. Clinically, the severity of traumatic brain injury (TBI) is defined by the GCS, and a GCS score $\leq 8$ is defined as severe TBI. Previous studies of TBI in patients over 65 years of age have shown that age and GCS score are independent predictors of an unfavorable outcome. ${ }^{24,27}$ Indeed, all patients with severe TBI were dependent in daily living activities 6 months after injury, and the mortality rate was 24 times higher than that in patients with a good GCS score. ${ }^{27}$ Similarly, the severity of aSDH, as part of TBI, has been reported to be an independent predictor of poor prognosis in several studies observing a younger cohort of patients. ${ }^{2,3,21,28}$ Our analysis of elderly patients over 80 years of age showed the same results, suggesting that for either young or old patients, the severity of aSDH is the 
TABLE 2. Favorable and unfavorable functional outcome at the 3-month follow-up

\begin{tabular}{|c|c|c|c|c|c|c|c|}
\hline \multirow[b]{2}{*}{ Parameter } & \multirow{2}{*}{$\begin{array}{c}\text { All } \\
\text { (no. }[\%])\end{array}$} & \multirow{2}{*}{$\begin{array}{l}\text { Favorable Outcome } \\
\text { (no. [\%]) }\end{array}$} & \multirow{2}{*}{$\begin{array}{l}\text { Unfavorable Outcome } \\
\text { (no. [\%]) }\end{array}$} & \multicolumn{2}{|c|}{ Univariate Analysis } & \multicolumn{2}{|c|}{ Multivariate Analysis } \\
\hline & & & & $\mathrm{OR}(95 \% \mathrm{Cl})$ & p Value & OR $(95 \% \mathrm{Cl})$ & $p$ Value \\
\hline No. of patients & 56 & 20 & 36 & & & & \\
\hline Mean age in yrs & $85.1 \pm 3.9$ & $85.2 \pm 4.1$ & $85.1 \pm 3.8$ & & NS & & \\
\hline Female sex & $24(42.8)$ & $10(50)$ & $14(38.9)$ & & NS & & \\
\hline Trauma & $38(67.8)$ & $14(70)$ & $24(66.7)$ & & NS & & \\
\hline $\begin{array}{l}\text { Timing of op after the 1st } 24 \\
\text { hrs of admission }\end{array}$ & $35(62.5)$ & $13(65)$ & $22(61.1)$ & & NS & & \\
\hline Mean hospital stay in days & $9.6 \pm 6.5$ & $11.9 \pm 7.2$ & $8.36 \pm 5.8$ & $3.0(0.94-9.54)$ & 0.07 & & NS \\
\hline \multicolumn{8}{|l|}{ Hematoma side } \\
\hline Lt & $24(42.8)$ & $9(45)$ & $15(41.7)$ & & NS & & \\
\hline $\mathrm{Rt}$ & $27(48.2)$ & $8(40)$ & $19(52.8)$ & & NS & & \\
\hline Both & $5(8.9)$ & $3(15)$ & $2(5.6)$ & & NS & & \\
\hline Mean hematoma vol in $\mathrm{cm}^{3}$ & $114.0 \pm 53.4$ & $114.7 \pm 52.7$ & $113.6 \pm 54.6$ & & NS & & \\
\hline Mean midline shift in mm & $8.7 \pm 6.8$ & $8.3 \pm 5.5$ & $8.9 \pm 7.5$ & & NS & & \\
\hline Admission GCS score $\leq 8$ & $29(51.8)$ & $6(30)$ & $23(63.9)$ & $4.1(1.3-13.3)$ & 0.02 & & NS \\
\hline GCS score $\leq 8$ at 24 hrs postop & $31(55.4)$ & $3(15)$ & $28(77.8)$ & $19.8(4.6-85.2)$ & $<0.0001$ & $18.2(4.0-82.5)$ & $<0.0001$ \\
\hline Rebleeding & $11(19.6)$ & $2(10)$ & $9(25)$ & & NS & & \\
\hline Anticoagulation & $42(75)$ & $13(65)$ & $29(80.6)$ & & NS & & \\
\hline Seizure & $23(44.2)^{*}$ & $5(25)$ & $18(56.2) \dagger$ & $3.9(1.1-13.2)$ & 0.04 & & NS \\
\hline Preop comorbidities $\geq 5$ & $31(55.4)$ & $6(30)$ & $25(69.4)$ & $5.3(1.6-17.4)$ & 0.006 & $9.7(1.0-100.5)$ & $<0.05$ \\
\hline Preop comorbidities $\geq 6$ & $12(21.4)$ & $1(5)$ & $11(30.6)$ & $8.4(1.0-70.5)$ & 0.04 & & NS \\
\hline \multicolumn{8}{|l|}{ Preop comorbidities } \\
\hline Hypertension & $46(82.1)$ & $17(85)$ & $29(80.6)$ & & NS & & \\
\hline Atrial fibrillation & $26(46.4)$ & $6(30)$ & $20(55.6)$ & $2.9(0.9-9.3)$ & 0.09 & & NS \\
\hline Type 2 diabetes & $18(32.1)$ & $3(15)$ & $15(41.7)$ & $4.0(1.0-16.3)$ & 0.07 & & NS \\
\hline Cardiovascular disease & $37(66.1)$ & $12(60)$ & $25(69.4)$ & & NS & & \\
\hline Respiratory insufficiency & $15(26.8)$ & $4(20)$ & $11(30.6)$ & & NS & & \\
\hline Renal failure & $8(14.3)$ & $1(5)$ & $7(19.4)$ & & NS & & \\
\hline Hematological disease & $6(10.7)$ & $1(5)$ & $5(13.9)$ & & NS & & \\
\hline Metabolic disease & $42(75)$ & $13(65)$ & $29(80.6)$ & & NS & & \\
\hline Previous stroke & $8(14.3)$ & $1(5)$ & 7 (19.4) & & NS & & \\
\hline Pneumonia & $25(44.6)$ & $7(35)$ & $18(50)$ & & NS & & \\
\hline Sepsis & $3(5.4)$ & $1(5)$ & $2(5.6)$ & & NS & & \\
\hline
\end{tabular}

Mean values are expressed with standard deviations. A low GCS score 24 hours after operation $(p<0.0001)$ and comorbidities $\geq 5(p=0.05)$ were highly significant predictors of an unfavorable outcome at 3 months' follow-up.

* Percentage based on a total of 52 patients since 4 patients were excluded due to an uncertain seizure status (no EEG).

† Percentage based on a total of 32 patients since 4 patients were excluded due to an uncertain seizure status (no EEG).

key predictor of functional outcome. Besides a low GCS score, pneumonia was an independent predictor of an unfavorable functional outcome at discharge. One of the most frequent complications in the intensive care unit is the development of pneumonia. Several studies have reported an association between pneumonia and prognosis in the patient regardless of underlying illness..$^{11,12}$ One recent retrospective study even described the influence of pneumonia on functional outcome up to 5 years after insult..$^{11}$ In our study, pneumonia was not a predictor of an unfavorable long-term outcome; however, this might be dependent on multiple factors such as the beginning of treatment, the type of microorganism, the type of pneumonia, and the general condition of the patient.
At the FU, an additional predictor of an unfavorable outcome was seizures, which are known to be strongly associated with aSDH. The incidence of seizures in patients with aSDH is between $24 \%$ and $36 \%$ and has been shown to be related to poor functional and social outcomes. ${ }^{9,17}$, 20-22 Despite a decreasing risk of developing seizures and epilepsy over time, the risk persists for up to 10 years, which could be one explanation for the negative influence on long-term functional outcome. ${ }^{4}$ Predictors of seizures in elderly patients were a low GCS score 24 hours after operation and a left-sided hematoma, similar to the previously published results by Rabinstein et al. ${ }^{21}$ Since elderly patients with comorbidities have clinical fluctuation more often than younger patients, the diagnosis of seizure may 
TABLE 3. Predictors of seizure in patients 80 years of age and older with aSDH

\begin{tabular}{|c|c|c|c|c|c|}
\hline \multirow[b]{2}{*}{ Parameter } & \multirow{2}{*}{$\begin{array}{c}\text { All } \\
\text { (no. }[\%)]\end{array}$} & \multirow{2}{*}{$\begin{array}{l}\text { Seizures } \\
\text { (no. }[\%)]\end{array}$} & \multirow{2}{*}{$\begin{array}{c}\text { No Seizures } \\
\text { (no. [\%)] }\end{array}$} & \multicolumn{2}{|c|}{ Univariate Analysis } \\
\hline & & & & OR $(95 \% \mathrm{Cl})$ & $\mathrm{p}$ Value \\
\hline No. of patients & 64 & 28 & 36 & & \\
\hline Mean age in yrs & $85.2 \pm 3.9$ & $85.5 \pm 4.0$ & $84.9 \pm 3.8$ & & NS \\
\hline Female sex & $28(43.8)$ & $9(32.1)$ & $19(52.8)$ & & NS \\
\hline Trauma & $47(73.4)$ & $19(67.8)$ & $28(77.8)$ & & NS \\
\hline Timing of op after the 1 st $24 \mathrm{hrs}$ of admission & $17(26.6)$ & $9(32.1)$ & $8(22.2)$ & & NS \\
\hline Mean hospital stay in days & $10.0 \pm 6.9$ & $10.2 \pm 6.2$ & $9.9 \pm 7.5$ & & NS \\
\hline \multicolumn{6}{|l|}{ Hematoma side } \\
\hline Lt & $30(46.9)$ & $18(64.3)$ & $12(33.3)$ & $3.6(1.3-10.2)$ & $\leq 0.02$ \\
\hline $\mathrm{Rt}$ & $30(46.9)$ & $10(35.7)$ & $20(55.6)$ & & NS \\
\hline Both & $4(6.2)$ & $0(0)$ & $4(11.1)$ & & NS \\
\hline Mean hematoma vol in $\mathrm{cm}^{3}$ & $106.3 \pm 50.6$ & $105.1 \pm 49.1$ & $107.3 \pm 51.8$ & & NS \\
\hline Mean midline shift in mm & $7.8 \pm 5.8$ & $8.1 \pm 6.8$ & $7.5 \pm 5.1$ & & NS \\
\hline Admission GCS score $\leq 8$ & $30(46.9)$ & $16(57.1)$ & $14(38.9)$ & & \\
\hline GCS score $\leq 8$ at 24 hrs postop & $35(54.7)$ & $20(71.4)$ & $15(41.7)$ & $3.5(1.2-10.0)$ & $\leq 0.02$ \\
\hline Anticoagulation & $49(76.6)$ & $23(82.1)$ & $26(72.2)$ & & NS \\
\hline Rebleeding & $12(18.8)$ & $4(14.3)$ & $8(22.2)$ & & NS \\
\hline \multicolumn{6}{|l|}{ Preop comorbidities } \\
\hline Hypertension & $54(84.4)$ & $21(75)$ & $33(91.7)$ & & NS \\
\hline Atrial fibrillation & $29(45.3)$ & $14(50)$ & $15(41.7)$ & & NS \\
\hline Type 2 diabetes & $26(40.6)$ & $13(46.4)$ & $13(36.1)$ & & NS \\
\hline Cardiovascular disease & $44(68.8)$ & $17(60.7)$ & $27(75)$ & & NS \\
\hline Respiratory insufficiency & $20(31.2)$ & 9 (32.1) & $11(30.6)$ & & NS \\
\hline Renal failure & $14(21.9)$ & $7(25)$ & 7 (19.4) & & NS \\
\hline Hematological disease & $8(12.5)$ & $5(17.8)$ & $3(8.3)$ & & NS \\
\hline Metabolic disease & $49(76.6)$ & $24(85.7)$ & $25(69.4)$ & & NS \\
\hline Previous stroke & $9(14.1)$ & $4(14.3)$ & $5(13.9)$ & & NS \\
\hline Pneumonia & $33(51.6)$ & $15(53.6)$ & $18(50)$ & & NS \\
\hline Sepsis & $3(4.7)$ & $1(3.6)$ & $2(5.6)$ & & NS \\
\hline
\end{tabular}

not be trivial. We assume that the left hemisphere itself does not exhibit higher epileptogenicity than the right side, but the clinical manifestation of left-sided seizure with aphasia and diminished consciousness obviously prompts an increased diagnosis of seizures. This highlights the need for routine and timely EEG diagnostics to detect seizures, so that antiepileptic treatment can be started in a timely manner.

To date, the decision for surgical management in elderly patients with aSDH is still a matter of controversy. In our study, $90 \%$ of patients with aSDH underwent a surgical procedure (up-front surgery, 56 patients; delayed surgical treatment, 5 patients). Patients who were comatose on admission and underwent up-front surgical treatment (24 patients) had significantly higher mortality and a higher rate of an unfavorable outcome than the patients with a better clinical status. Despite those facts, $23 \%$ of the initially comatose patients still had a favorable outcome at FU, indicating the necessity and benefit of a neurosurgical procedure even in elderly patients with a comatose status.
In our study, $37 \%$ survived, which is not different from the rate among younger patients. ${ }^{2,8,17,23}$ Furthermore, in contrast to other studies using survival rate as the main end point in elderly patients, we tried to be more precise by categorizing survivors as having a favorable or an unfavorable outcome, specifically referring to quality of life. ${ }^{17}$ Therefore, to survive with a good quality of life, the decision for surgical treatment should be made after evaluating a patient for individual risk factors. Given our data, surgical treatment is indicated in comatose patients with fewer than 5 comorbidities and should be seriously considered in comatose patients with more than 6 comorbidities.

On the other hand, patients with a better clinical status profited considerably from neurosurgical intervention. In particular, the effect clearly appears at the FU. More than $50 \%$ of patients had a favorable outcome at FU, indicating a clear surgical advantage. Similar results were reported by Rabinstein et al. in a study of patients with aSDH without any age restrictions. ${ }^{21}$ Therefore, in patients with a noncomatose status, surgery can lead to a reasonable rate 
of favorable outcomes and is strongly recommended. In terms of bur hole treatment, if it is possible, it seems to be as effective as other surgical procedures and to have lower postoperative mortality and morbidity rates and a trend toward lower seizure rates. Hence, in patients with a good clinical status and multiple comorbidities, a delayed bur hole treatment could be an alternative, despite the fact that the majority of patients would need an emergent operation.

This study has several limitations. First, we did not differentiate elderly patients who did or did not undergo rehabilitation postoperatively. It is obvious that elderly patients profit from rehabilitation depending on its intensity and quality; however, patient compliance cannot be disregarded. Since all treatment decisions were made after conversations with and considering any requests made by the patient and his or her family, we concluded that rehabilitation might not greatly affect the results. However, based on our data, further treatment in an internal unit should be discussed with patients with more than 4 comorbidities before transfer to a secondary neurological rehabilitation center. Second, functional outcome was only measured by the GOS, which is widely used in TBI research to determine patient outcome. However, it does not discriminate the specific functional or cognitive status of the patient. Unfortunately, most of the patients were unable to undergo preoperative functional testing to have a baseline for comparison between their preoperative and postoperative statuses. Third, the study was retrospective in nature, thus having inherent limitations.

\section{Conclusions}

Over the last decade, the incidence of aSDH in elderly patients has continuously increased. To date, more than $50 \%$ of the aSDH patients admitted to our institution were 80 years or older. In this cohort, the overall mortality rate was $28 \%$ at discharge and $48 \%$ at FU. Outcome at discharge was dependent on the severity of aSDH, whereas outcome at FU was dependent on the accumulation of comorbidities. Overall, $36 \%$ of our patients had a favorable outcome. In 2 subgroups-noncomatose patients or patients with fewer than 5 comorbidities-more than 50\% had a favorable outcome at the FU. On the other hand, none of the patients with more than 6 comorbidities had survived by the FU. Given these results, surgical treatment may be beneficial and indicated in elderly aSDH patients, especially in noncomatose patients and in comatose patients with fewer than 6 comorbidities. In patients with more than 6 comorbidities, surgical treatment should be seriously discussed. In particular, in cases of poor status and delayed recovery after operation, the risk of seizures is high and the use of prophylactic antiepileptic treatment should be considered.

\section{Acknowledgments}

We thank Marina Heibel for her excellent technical support.

\section{References}

1. Busl KM, Prabhakaran S: Predictors of mortality in nontraumatic subdural hematoma. J Neurosurg 119:1296-1301, 2013
2. Cagetti B, Cossu M, Pau A, Rivano C, Viale G: The outcome from acute subdural and epidural intracranial haematomas in very elderly patients. Br J Neurosurg 6:227-231, 1992

3. de Rooij SE, Abu-Hanna A, Levi M, de Jonge E: Factors that predict outcome of intensive care treatment in very elderly patients: a review. Crit Care 9:R307-R314, 2005

4. Englander J, Bushnik T, Duong TT, Cifu DX, Zafonte R, Wright J, et al: Analyzing risk factors for late posttraumatic seizures: a prospective, multicenter investigation. Arch Phys Med Rehabil 84:365-373, 2003

5. Frontera JA, Egorova N, Moskowitz AJ: National trend in prevalence, cost, and discharge disposition after subdural hematoma from 1998-2007. Crit Care Med 39:1619-1625, 2011

6. Gebel JM, Sila CA, Sloan MA, Granger CB, Weisenberger $\mathrm{JP}, \mathrm{Green} \mathrm{CL}$, et al: Comparison of the $\mathrm{ABC} / 2$ estimation technique to computer-assisted volumetric analysis of intraparenchymal and subdural hematomas complicating the GUSTO-1 trial. Stroke 29:1799-1801, 1998

7. Hamed M, Schuss P, Daher FH, Borger V, Güresir Á, Vatter $\mathrm{H}$, et al: Acute traumatic subdural hematoma: surgical management in the presence of cerebral herniation-a singlecenter series and multivariate analysis. World Neurosurg 94:501-506, 2016

8. Howard MA III, Gross AS, Dacey RG Jr, Winn HR: Acute subdural hematomas: an age-dependent clinical entity. J Neurosurg 71:858-863, 1989

9. Jennett B: Epilepsy and acute traumatic intracranial haematoma. J Neurol Neurosurg Psychiatry 38:378-381, 1975

10. Jüttler E, Unterberg A, Woitzik J, Bösel J, Amiri H, Sakowitz OW, et al: Hemicraniectomy in older patients with extensive middle-cerebral-artery stroke. N Engl J Med 370:1091-1100, 2014

11. Kesinger MR, Kumar RG, Wagner AK, Puyana JC, Peitzman AP, Billiar TR, et al: Hospital-acquired pneumonia is an independent predictor of poor global outcome in severe traumatic brain injury up to 5 years after discharge. J Trauma Acute Care Surg 78:396-402, 2015

12. Khajavikhan J, Vasigh A, Khani A, Jaafarpour M, Kokhazade T: Outcome and predicting factor following severe traumatic brain injury: a retrospective cross-sectional study. J Clin Diagn Res 10:PC16-PC19, 2016

13. Koç RK, Akdemir H, Oktem IS, Meral M, Menkü A: Acute subdural hematoma: outcome and outcome prediction. Neurosurg Rev 20:239-244, 1997

14. Leung GK, Ng GK, Ho W, Hung KN, Yuen WK: Impact of a multidisciplinary trauma team on the outcome of acute subdural haematoma. Injury 43:1419-1422, 2012

15. Luerssen TG, Klauber MR, Marshall LF: Outcome from head injury related to patient's age. A longitudinal prospective study of adult and pediatric head injury. J Neurosurg 68:409-416, 1988

16. Mulligan P, Raore B, Liu S, Olson JJ: Neurological and functional outcomes of subdural hematoma evacuation in patients over 70 years of age. J Neurosci Rural Pract 4:250-256, 2013

17. Okazaki T, Hifumi T, Kawakita K, Nakashima R, Matsumoto A, Shishido H, et al: Association between comorbidities, nutritional status, and anticlotting drugs and neurological outcomes in geriatric patients with traumatic brain injury. World Neurosurg 93:336-340, 2016

18. Panczykowski DM, Okonkwo DO: Premorbid oral antithrombotic therapy and risk for reaccumulation, reoperation, and mortality in acute subdural hematomas. J Neurosurg 114:47-52, 2011

19. Phuenpathom N, Choomuang M, Ratanalert S: Outcome and outcome prediction in acute subdural hematoma. Surg Neurol 40:22-25, 1993

20. Pollandt S, Ouyang B, Bleck TP, Busl KM: Seizures and 
epileptiform discharges in patients with acute subdural hematoma. J Clin Neurophysiol 34:55-60, 2017

21. Rabinstein AA, Chung SY, Rudzinski LA, Lanzino G: Seizures after evacuation of subdural hematomas: incidence, risk factors, and functional impact. J Neurosurg 112:455-460, 2010

22. Raj R, Mikkonen ED, Kivisaari R, Skrifvars MB, Korja M, Siironen J: Mortality in elderly patients operated for an acute subdural hematoma: a surgical case series. World Neurosurg 88:592-597, 2016

23. Ryan CG, Thompson RE, Temkin NR, Crane PK, Ellenbogen RG, Elmore JG: Acute traumatic subdural hematoma: current mortality and functional outcomes in adult patients at a Level I trauma center. J Trauma Acute Care Surg 73:1348-1354, 2012

24. Seifi A, Asadi-Pooya AA, Carr K, Maltenfort M, Emami M, Bell R, et al: The epidemiology, risk factors, and impact on hospital mortality of status epilepticus after subdural hematoma in the United States. SpringerPlus 3:332, 2014

25. Servadei F: Prognostic factors in severely head injured adult patients with acute subdural haematoma's. Acta Neurochir (Wien) 139:279-285, 1997

26. Taussky P, Hidalgo ET, Landolt H, Fandino J: Age and salvageability: analysis of outcome of patients older than 65 years undergoing craniotomy for acute traumatic subdural hematoma. World Neurosurg 78:306-311, 2012

27. Utomo WK, Gabbe BJ, Simpson PM, Cameron PA: Predictors of in-hospital mortality and 6-month functional outcomes in older adults after moderate to severe traumatic brain injury. Injury 40:973-977, 2009

28. Weimer JM, Gordon E, Frontera JA: Predictors of functional outcome after subdural hematoma: a prospective study. Neurocrit Care 26:70-79, 2017

29. Won SY, Bruder MG, Mersmann J, Seifert V, Senft C: Dislocated pacemaker electrode simulating focal epileptic state in a patient with subdural hematoma-case report and review of the literature. World Neurosurg 88:696.e1-696.e4, 2016

\section{Disclosures}

Adam Strzelczyk reports receiving grants and personal fees from Bayer HealthCare, Boehringer Ingelheim, Desitin Arzneimittel, Eisai, Pfizer, Sage Therapeutics, and UCB Pharma for work outside the submitted study.

\section{Author Contributions}

Conception and design: Won, Freiman, Konczalla. Acquisition of data: Won, Dubinski, Brawanski. Analysis and interpretation of data: Won, Dubinski, Brawanski. Drafting the article: Won, Dubinski, Konczalla. Critically revising the article: Won, Strzelczyk, Seifert, Freiman, Konczalla. Reviewed submitted version of manuscript: Won, Dubinski, Strzelczyk, Seifert, Freiman, Konczalla. Approved the final version of the manuscript on behalf of all authors: Won. Statistical analysis: Won, Brawanski, Strzelczyk, Konczalla. Administrative/technical/material support: Won, Strzelczyk, Freiman, Konczalla. Study supervision: Won, Strzelczyk, Seifert, Freiman.

\section{Supplemental Information Videos}

Video Abstract. https://vimeo.com/236443975.

\section{Correspondence}

Sae-Yeon Won, Department of Neurosurgery, Goethe-University, 2-16 Schleusenweg, Frankfurt am Main, Hessen 60528, Germany. email: sae-yeon.won@kgu.de. 